Swarthmore College

Works

Fall 2018

\title{
Lesson Plan For Teaching Four Stories Featuring Multi/Mixed Identities
}

Sierra Sweeney , '21

Peter Schmidt

Swarthmore College, pschmid1@swarthmore.edu

Follow this and additional works at: https://works.swarthmore.edu/fac-english-lit

Part of the English Language and Literature Commons

Let us know how access to these works benefits you

\section{Recommended Citation}

Sierra Sweeney , '21 and Peter Schmidt. (2018). "Lesson Plan For Teaching Four Stories Featuring Multi/ Mixed Identities". English Literature Faculty Works. DOI: 10.24968/2476-2458.engl.353

https://works.swarthmore.edu/fac-english-lit/353

\section{(c) (7) (8)}

This work is licensed under a Creative Commons Attribution-Noncommercial 4.0 License This work is brought to you for free by Swarthmore College Libraries' Works. It has been accepted for inclusion in English Literature Faculty Works by an authorized administrator of Works. For more information, please contact myworks@swarthmore.edu. 
Sierra Sweeney

Professor Peter Schmidt

English 71D, "The Short Story in the U.S."

Swarthmore College Fall 2018

\section{Lesson Plan for Teaching Four Stories Featuring Multi/Mixed Identities: \\ Charles Yu's "Third Class Superhero" \\ Karen Russell's "St. Lucy's Home for Girls Raised by Wolves" \\ Viet Nguyen's "The Americans" and \\ Gish Jen's "Who's Irish?"}

Fiction as a genre is well known for its ability to discuss a wide range of topics in a way that is both entertaining and empathetic. But while fictional pieces, especially the short story, are famous for creating narratives that help readers understand experiences unlike their own and characters unlike themselves, I would argue that fiction can also serve as a medium of selfreflection. As someone who identifies as multi-ethnic and multi-racial, understanding my identity through literature has been both eye-opening and difficult. Multi authors and works of fiction do exist. But they are rarely discussed as widely or taught in a way that focuses purely on their multi and mixed themes. This lesson plan exists to suggest strategies that teachers and professors may use to help comprehensively teach multi and non-multi students about the complexities and tensions surrounding mixed identities. - Sierra Sweeney

Note:

- These lesson plans can be used for both High School and College students.

- Teachers may teach stories together over the course of a week or more, or may choose to teach only one or two stories together. Recommend pairing at least two stories together.

- More than one class session (45-60min) is likely needed for "St. Lucy's Home for Girls Raised by Wolves" and "Third Class Superhero."

- Table of Contents for the upcoming pages: Learning Goals followed by individual lesson plans for teaching each of the four stories listed above. This document 


\section{concludes with a Bibliography of further readings on multi identities, followed by the author's reflections on devising these lesson plans and a Works Cited.}

\section{Learning Goals:}

These lesson plans are designed to help high school and college/university students comprehensively examine multi and mixed identities through fantastical and everyday stories. For this lesson, multi is defined as an identity that encompasses the mixed multi-ethnic, racial, and/or cultural heritages of an individual. Through each story, students will learn to see the diversity of multi experiences as well as the intersecting experiences of isolation, authenticity, identity erasure, and family conflict.

In "Third Class Superhero," students will be taught to consider the stress of dichotomies, choosing between different sides of oneself, through the exaggerated but nevertheless realistic superhero genre. Super power checklists and good-guy vs. bad-guy labels will reveal the internal tensions within mixed individuals as well as the societal identity expectations they are pushed to embody. Students will also learn to think critically about Nathan's narration and the motivations behind his various attempts to be authentic and recognized by the superhero community/institution. They will also learn the difficulties and consequences behind the pursuit for authenticity and hopefully view Nathan's character as not entirely bad or good, but as a complicated in-between.

After learning about the difficult relationship multi individuals can have with identity, students will learn about the heartbreaking process of systematic erasure through historical research on Native American Boarding schools as well as through “St. Lucy's Home for Girls Raised by Wolves.” Connecting their research to Russell's story, students will discuss the different aspects that contribute to identity such as language, food, and community and how a 
system such as St. Lucy's works to erase culture and visibility. Students will follow Claudette's story and through her reflective narration witness her struggle to assimilate to an imposing culture. They will also interpret the tensions held against those who can and cannot assimilate well such as Jeannette and Mirabella. Students will also learn about the term code-switching and discuss the mental and physical challenge this poses for the girls at St. Lucy's. While St. Lucy's attempts to convince the reader that balancing between two worlds is simple, students will discover that in addition to code-switching being extremely difficult, the St. Lucy's doctrine also emphasizes erasure and not balance.

While St. Lucy's explores the erasure of mixed identities, “The Americans" and "Who's Irish” will instead push students to examine the dynamics and tensions of mixed families. In “The Americans," students will compare and contrast Carver and Claire's experiences with discrimination as well as their search for belonging. They will recognize that while Carver dealt with racial discrimination that led him to joining the army, Claire, feeling isolated by strangers and members of her community alike, had to search for belonging in the very place her father went to war with. This will reinforce the idea that multi-racial children often experience similar as well as very unique difficulties in comparison to their parents.

Students will continue to examine the role of mixed identities in families in "Who's Irish?" Through this story students will learn about the language used to refer to multi children as well as the different "sides" at conflict with each other within families and individuals. The narrator's language will teach children to understand that while there is conflict surrounding mixed identities, there are also exchanges and resolutions. 
After reading two or all four stories, students will learn to see how complex navigating identity can be and how limiting labels and dichotomies can be for those who do not perfectly fit within the expectations of society and their own communities.

\section{Lesson Plan for Teaching Charles Yu's "Third Class Superhero" (pg. 1-24)}

This story appeals to the Multi identity theme extensively. To get students to think about Multi identities and superheroes, begin with small group discussions about mainstream superheroes and dichotomies that exist within the superhero and comic genre. This can include the prevalent good vs. evil or hero vs. villain dichotomy that is usually at play, a discussion of super powers, or a discussion about alter egos (Bruce Wayne, Peter Parker, Tony Stark, etc.). This will hopefully show how multiple identities are crucial to the superhero genre and will help illustrate how these multi themes can be applied to real life, transitioning to the messages in Yu's story. Then proceed with the following teacher and class led discussion:

\section{Prerequisite this lesson by teaching the different styles of narration. Examples:}

First Person Narration: When the story is narrated by the point of view of one character, allowing the audience to experience that character's beliefs and thoughts. Note that many first person narrators can be unreliable because the reader only hears their side of the story. The reader is limited to the first person narrator's thoughts and knowledge and should therefore question their point of view.

Close Third Person Narration: Narration that focuses on the beliefs and experiences of one person while not using their actual "voice." A reader can often notice when the narrator own voice appears to comment on what is happening to the story's point-of-view character. 
Indirect Narration: Quoting the thoughts and feelings of a character without the use of quotation marks.

Free Indirect Narration: Using group wisdom or language of multiple people or a large group of people. (Discuss with students the impact of this style. How does it utilize dramatic irony, skepticism, or sympathy?)

Omniscient Narration: All-knowing narrators. Is often used with third person distant narration to inform the readers about multiple facts and perspectives within the story.

\section{Discussion Questions and Passages:}

1.) In Yu's story Nathan describes having to take an exam and reapply for his "good-guy card" in order to still be labeled as a hero. During this exam he has to describe himself and check boxes to explain his identity and powers. But as the reader learns, "There's no box to check for my power, so I write it in. Try to pretty it up a little" (Yu, 12). Explain the significance of Nathan's inability to label his powers and his discomfort with choosing between "Good Guy" and "Bad Guy." Why does Yu depict the superhero process as so bureaucratic and limiting? What does Nathan's difficulty with finding a label for himself add to the themes in the story?

2.) At the beginning of the story Nathan believes flying to be the one thing that could make a difference when it comes to becoming a super hero. He essentially believes that flying will make his identity as a "Good Guy" more authentic, but at the end of the story we see that even with the ability to fly, Nathan still does not perfectly fit in as a superhero. What aspects of Nathan's identities are revealed when he finally does learn how to fly and why are these important to the theme of multi? What does authenticity mean in the context of 
identity? Why does his new ability to fly not solve all of his identity problems? Refer to pages 22-24.

a. "I was the bad guy in this story. And I know it. But I wish I wasn't a bad guy. Do I get points for that? What does that make me? What kind of guy?" (Yu, 24).

b. "I'm flying, look at me, a bad guy in a good-guy costume, no more rules. Dear Applicant. Your help is not needed. The world is just fine without you... I'm a good person wrapped in a mediocre soul. I want to be better. I really do. But even now in my greatest moment I know this is as good as it will ever get for me and it's not that good. I have a small heart, a dark heart, a heart filled with exactly equal amounts of good and evil..." (Yu, 24).

3.) Going back to the discussion at the beginning of class, why are superheroes and the language of superheroes good mediums for talking about mixed identities? What do the costumes (see quote about costumes on page 18), the superpowers, and the labels mean? Can superhero fantasy be applied to the real world?

a. "That is what a costume is supposed to look like, I think, when it fits" (Yu, 18).

\section{4.) Possible Assignment: Ask students to identify the narration style of this story in} small pairs and reconvene to discuss their choices (Close $1^{\text {st }} / 3^{\text {rd }}$ person). Ask students what they believe this style of narration does for the story. What impact did this narration have on their interpretation of the story?

a. While Nathan is a complex character who does good and bad things with different motivations, how does his first person point of view make the audience feel? Do we see him as a good or bad guy? How did his first person narration make you feel about his thoughts and actions in scenes such as when he betrays the other 
superheroes he works with? How should we understand why he betrays other superheroes? Can we judge him?

b.

\section{Lesson Plan for Teaching Karen Russell's “St. Lucy's Home for Girls Raised by} Wolves" (pgs. 225-246)

Russell's story is extremely relevant to the theme of multi identity and deeply explores the process of assimilation and "code switching" as well as the difficulty and consequences surrounding the rejection of part of one's identity. In addition to this, “St. Lucy's Home for Girls Raised by Wolves" is clearly making a commentary on the erasure of Indigenous identity in Native American Boarding Schools. This is very important to the story, and I believe should be discussed ahead of time so that students are informed of this historical connection while reading the story. Ask your students to work in groups or alone and research historical and personal accounts of Native American Boarding schools before class and then hold a discussion on the information they found during class. Call on each group/individual if conversation does not flow organically. (Can be graded)

Here are some online resources you may suggest for your students/show in class. But I would encourage students to find their own resources, especially first person accounts.

a. https://www.history.com/news/how-boarding-schools-tried-to-kill-the-indian-

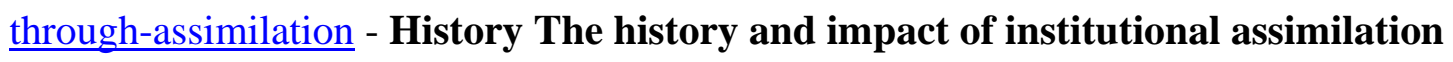

b. https://www.npr.org/templates/story/story.php?storyId=16516865 - NPR The historical and lasting impact of Indian Boarding Schools

c. https://www.pbs.org/video/unspoken-americas-native-american-boarding-schoolsoobt1r/ - PBS Documentary 


\section{Discussion Questions and Passages:}

Simple (or perhaps not) question to ask at the beginning of class and then revisit at the end of the discussion: Why wolves and wolf-related language?

1.) As said before, St. Lucy's alludes to the Native American Boarding schools in that it too removes children from their families and attempts to change their identities and culture. How do St. Lucy's assimilation attempts relate to or differ from those you have learned about historically? What are the different aspects that construct the identity and culture of a person? What happens when those aspects are forcibly erased? Examples in the following passages:

a. "The oldest sister howled something awful and inarticulable, a distillate of hurt and panic, half-forgotten hunts and eclipsed moons. Sister Maria nodded and scribbled on a yellow legal pad. She slapped on a nametag: HELLO, MY NAME IS ! 'Jeanette it is"' (Russell, 228).

b. "[Mirabella] was still loping around on all fours (which the nuns had taught us to see looked unnatural and ridiculous - we could barely believe it now, the shame of it, that we used to locomote like that!)" (Russell, 231).

2.) Also look at the different St. Lucy's "Stages" that are throughout the story (Pgs. 225, $229,235,240,245)$. What purpose do these small sections serve narratively throughout the story? What do these sections tell us about the assimilation process that the girls are going through? How do you interpret the language and tone of these sections in relation to what they are stating?

a. In response to Stage 5 (pg. 245), discuss "code-switching," the act of changing oneself to project a specific identity in specific environments, and ask your 
students to define it in small groups and to share if they believe they have experienced code-switching before. You may reconvene after and see if students are willing to share their experiences. Implore them to think, do they act differently with different groups of friends? When they are at school and at home? When they are with those of the same race/ethnicity/background and those who are not?

3.) Continuing with the idea of erasure, in one scene Claudette describes how her and her sisters tried to "mark their territory" at St. Lucy's. Why are the girls doing this and how does it relate to identity? How do visibility and belonging relate back to identity? Here and in many places, Claudette uses many "we" statements, what is the significance of this group language and narration? How do their combined experiences relate to what we have learned historically?

a. "In the beginning, we drank gallons of bathwater as part of a collaborative effort to mark our territory. We puddled up the yellow carpet of old newspapers. But later, when we returned to the bedroom, we were dismayed to find all traces of the pack musk had vanished. Someone was coming in and erasing us. We sprayed and sprayed every morning; and every night, we returned to the same ammonia eradication. We couldn't make our scent stick here; it made us feel invisible. Eventually we gave up" (Russell, 230).

4.) Notice how Claudette uses free indirect first person narration, which is apparent in her discussion of her own feelings as well as the group's thoughts and feelings. Ask your students what they believe her narration style is. How should we interpret Claudette's narration? It also seems as if she is speaking as an adult about her past experience, what 
effect does this have? What is her tone and how does it shape the way we perceive her experiences and actions at St. Lucy's? Additionally, Claudette often repeats the phrase, "Mouth shut—shoes on feet" why do you think she does this? Examples of narration:

a. "We liked to speculate about this [not adapting] before bedtime, scaring ourselves with stories of catastrophic bliss. It was a disgrace, the failure that we all guiltily hoped for in our hard beds. Twitching with the shadow question: Whatever will become of me?"' (Russell, 233).

b. '“'Yes, I know what it is that you mean,' I snapped. (That's probably a little narrative embellishment on my part; it must have been months before I could really 'snap' out words)” (Russell, 242).

5.) In addition to discussing the experiences of the pack, Claudette also focuses on how Mirabella and Jeanette assimilate differently. She explains that, "The pack hated Jeanette, but we hated Mirabella more" (Russell, 233). How do you interpret the tensions surrounding Jeanette who assimilates well, and Mirabella who struggles to do so?

a. There is also a scene where Claudette finds Jeanette crying after reading this line, "The lake-water was reinventing the forest and the white moon above it, and wolves lapped up the cold reflection of the sky" (Russell, 239). Why do you think these lines are so significant to Jeanette and what does this scene say about Jeanette's character and assimilation process? Is she as content with assimilating as she is portrayed?

6.) And finally, look at the description of the wolf girls' parents, the werewolves, what are their experiences in society and how do they relate to the theme of multi/mixed identities? Why are they "ostracized" by humans and wolves? How do their experiences 
shape and relate to their children's? Why do you think the parents "sent" them to the boarding school in the first place? How do you think the girls interacted with their family when they returned?

a. "Our mothers and fathers were werewolves. They lived an outsider's existence in caves at the edge of the forest, threatened by frost and pitchforks. They had been ostracized by the local farmers for eating their silled fruit pies and terrorizing the heifers. They had ostracized the local wolves by having sometimes-thumbs, and regrets, and human children... We couldn't keep up with the purebred wolves, but we never stopped crawling. We spoke a slab-tongued pidgin in the cave, inflected with frequent howls. Our parents wanted something better for us; they wanted us to get braces, use towels, be fully bilingual" (Russell, 227).

After going through important passages and questions, return to question asked at beginning of class: Why wolves? (Have answers changed or become more complex?)

\section{Lesson Plan for Teaching Viet Nguyen's “The Americans” (pgs. 125-149)}

For this story, as well as for "Who's Irish?" there are numerous important themes, but because this lesson plan focuses on multi and mixed identities, only these themes will be discussed. Both "The Americans" and "Who's Irish?" are well suited for discussing the tensions and dynamics within mixed families as well as the complexities surrounding multi children and their experiences. Because these stories are being read and discussed after "Third Class Superhero" and "St. Lucy's Home for Girls Raised by Wolves," preface student reading by prompting them to seek out multi identity topics in "The Americans" and "Who's Irish?" 
Ask students to break up into small groups and discuss what parts of the story they believe relate back to the multi theme and why. When you ask students to reconvene, invite them to share and then structure your discussion with the natural flow of their interests. If no one is willing to share, either call on each group and ask the other groups to respond, or proceed with lesson plan in the following order.

\section{Discussion Questions and Passages:}

1.) In "The Americans," Carver is not explicitly introduced as Black until page 131. It is interesting how this fact alters Carver's story and as a result, directly alters Claire's as well. Not only is the audience made aware of some deep-rooted tensions held between Carver and Claire, but we are also made aware of society's tensions with them. This in mind, ask students if they realized Carver is black and that Claire is a mixed before Nguyen explicitly tells us. Did you read Carver's and Claire's characters differently before their races were mentioned? How did this influence your understanding of the story? How would your interpretation of the story change if Carver and Claire were white?

2.) On page 132, Carver describes Claire's experiences with discrimination and microaggressions as a child and thinks back to his own experiences in college and the Air Force. Though the story could perhaps be interpreted as highlighting the differences between Carver and Claire, one could instead say that the story actually works to emphasize their similarities through their tensions with identity. After closely reading this paragraph, what are some similarities between Carver and Claire? At one point, Carver relates people asking him "What are you doing here?" to people asking Claire "What are 
you?" How do you interpret these experiences and Carver's comparison of the two? What else do you notice about the "guilty" language of Carver's passage?

a. "She said it matter-of-factly, without any of the melodrama of her adolescence, when she would come home from school sobbing at a slight from a peer or a stranger, some variation along the line of What are you? Her tears agonized Carver, making him feel guilty for delivering her into a world determined to put everybody in her proper place. He wanted to find the culprit who had hurt his daughter and beat some sense into the kid's head, but he restrained himself, as he had whenever he encountered the look in people's eyes that said What are you doing here? ... He was never where he was supposed to be. He had survived by focusing on his goal, ascending ever higher, refusing to see the sneers and doubt in his peripheral vision" (Nguyen, 132).

i. You may also ask, why is the story titled "The Americans?" Is this meant to show another similarity between Claire and Carver? How do you interpret the following scene in relation to the title: “'You're not a native,' Carver said. 'You're an American.' 'That's a problem I'm trying to correct"” (Nguyen, 130).

3.) After examining the similarities between the two, we must take a closer look at the causation for Carver and Claire's tension. It is interesting that two people, who were shunned their entire lives because of their identity, are written with such a tumultuous relationship. Carver and Claire both seem to desire the same thing, a sense of belonging, though they find it in different ways. How and where do they search for and find this 
sense of belonging? Why are their different experiences with belonging at odds with each other? Closely read the following passages:

a. “'I am home, Mom. It sounds strange, I don't know how to put it, but I feel like this is where I'm supposed to be. I have a Vietnamese soul.' 'That's the stupidest thing I've ever heard,' Carver shouted" (Nguyen, 134).

b. '“Haven't they seen tourists before?' Carver said. 'Not like us.' Claire unsealed a pack of cigarettes and lit one. 'We're a mixed bag.' 'They don't know what to make of us?' Michiko said. 'I'm used to it, but you're not.' 'Try being a Japanese wife at a Michigan air base in 1973.' 'Touché,' Claire said. 'Try being a black man in Japan,' Carver said. 'Or Thailand.' 'But you could always go home,' Claire said. 'There was always a place for you somewhere. But there's never been a place for me' (Nguyen, 131).

i. At this passage especially, discuss the differences and similarities between Claire and her parents. How are the experiences of a multi-racial child different from those of her parents?

4.) Keeping the multi and identity themes in mind, how do you interpret the ending? Do you believe that Claire and Carver's conflict is or will be resolved? What is the significance of Claire taking care of Carver in the last scene? Why is Carver crying? Refer to pages 147-149.

IV. Lesson Plan for Teaching Gish Jen's “Who's Irish?” (pgs. 1-16) After examining the family tensions between father and daughter in "The Americans," we will now continue to explore the complexities within multi families, especially 
generationally. This story brilliantly depicts the complex and often loaded interactions and transactions that occur within multi families. A reoccurring theme in this story is conflict between different "sides" such as the different sides of the Shea family, the Irish and Chinese sides of Sophie, and the different parenting styles. However, reading the story as only one of conflict would ignore the exchanges that also occur in mixed families, such as the narrator's use of Bess's language after living with her. Ask your students to break into groups and create a list of the different "sides" at play in this story. When you reconvene ask if they believe these sides are only in conflict with each other or if their relationship is more complex?

\section{Discussion Questions and Passages:}

1.) After discussing "sides" begin by exploring the language used to describe mixed children, specifically Sophie. Perform a close reading on the following passages. Why does Sophie's grandmother refer to her "Irish side" as "wild" and un-Chinese? At one point her grandmother comments on how Chinese her appearance is, how do you interpret her examination of Sophie's appearance? How do you interpret the Shea's response to Sophie's "brown surprise" skin? How and why are the appearances of mixed children discussed?

a. "Even I am happy, because there is more trouble with Sophie, but now I think I can help her Chinese side fight against her wild side" (Jen, 11).

b. "Sophie is three years old American age, but already I see her nice Chinese side swallowed up by her wild Shea side. She looks like mostly Chinese. Beautiful black hair, beautiful black eyes. Nose perfect size, not so flat looks like something fell down, not so large looks like some big deal got stuck in wrong face. Everything just right, only her skin is a brown surprise to John's family. So 
brown, they say. Even John say it. She never goes in the sun, still she is that color, he say. Brown. They say, Nothing the matter with brown. They are just surprised. So brown. Nattie is not that brown, they say. They say, It seems like Sophie should be a color between Nattie and John. Seems funny, a girl named Sophie Shea should be brown" (Jen, 6).

i. Additionally, with this passage, how does the indirect quotation and first person narration add to the story? What does it reveal about the Shea family's attitudes about Sophie's skin color?

ii. Also, why does the Shea family have the sense that Sophie should "be a color between Nattie and John?" How does this contrast with our narrator's opinions about Sophie's appearance?

2.) After she moves in with Bess, our narrator begins adopting similar phrases including "permanent resident." How do you interpret the ending scene where our narrator discusses her relationship with Bess and the Irish as opposed to her relationship with them at the beginning of the story? What does "honorary Irish" mean? Is the ending a resolution for the conflict between the different "sides" discussed earlier?

a. 'Of course, I shouldn't say Irish this, Irish that, especially now I am become honorary Irish myself, according to Bess. Me! Who's Irish? I say, and she laugh. All the same, if I could mention one thing about some of the Irish, not all of them of course, I like to mention this: Their talk just stick. I don't know how Bess Shea learn to use her words, but sometimes I hear what she say long time later. Permanent Resident. Not going anywhere" (Jen, 15-16). 
3.) Additional Assignment: Have students write a short blog post/reflection paper in which they should connect the themes in "The Americans" to those in "Who's Irish?" Ask them to specifically think about the characters and their narration, experiences, and tensions within these two stories. Also ask students to contemplate the endings of these two stories. What were the endings trying to achieve? Compare and contrast the endings in the reflection as well and how they relate to the mixed and multi theme of the lesson. (Can Be Graded).

\section{Suggested Optional Readings that Also Relate to the Multi/Mixed Theme}

You can recommend these books to students who are interested in pursuing this theme further or for exploring and using in class as well.

Hopkinson, Nalo. Skin Folk. "Precious.” Pages 247-255. Warner Books. 2001

Erdrich, Louise. “Fleur.” Pages 761-774. 1954. Oates, Joyce Carol. The Oxford Book of American Short Stories $2^{\text {nd }}$ Edition. Oxford University Press. Oxford, New York. 2013.

Jin, Ha. “Children as Enemies." Pages 799-805. 1956. Oates, Joyce Carol. The Oxford Book of American Short Stories $2^{\text {nd }}$ Edition. Oxford University Press. Oxford, New York. 2013. Sáenz, Benjamin Alire. Aristotle and Dante Discover the Secrets of the Universe. Simon \& Schuster Publishing, New York. 2012.

Peña, Matt de la. Mexican WhiteBoy. Delacorte Press, New York. 2008.

Prasad, Chandra. Mixed: An Anthology of Short Fiction on the Multiracial Experience. W.W. Norton Company. 2006. 


\section{Reflections on these lesson plans, by Sierra Sweeney}

As someone who identifies as multi-racial and multi-ethnic, creating a lesson plan that focused on the issues and experiences of mixed individuals that multi and non-multi students alike could understand was my goal. At first, I had a difficult time choosing my stories. A fair amount of short stories deal with the topic of mixed identities. So instead of choosing any story that discussed multi themes, I had to choose stories that spoke to the common experiences of multi-individuals, including code-switching, imposter syndrome, and family tensions.

Though at first it may seem like a story about a down on his luck superhero, "Third Class Superhero" dealt directly with themes of authenticity and identity labeling. It was an essential story choice to show students how mixed individuals struggle to navigate societal dichotomies and struggle to define their identity in relation to their communities. I was first worried that because of its fantastical content, students might fail to see the importance of Nathan's identity struggles and judge his actions harshly. To avoid this, I decided to first begin by discussing mainstream superheroes and alter egos to invest students and then jump into discussion about the key moments of discomfort for Nathan, primarily when he has to re-apply for his "Good-guy card.” Discussing narration was also crucial for helping students understand Nathan's discomfort and therefore understand the choices he makes more empathetically.

I similarly worried that the deeper themes of "St. Lucy's Home for Girls Raised by Wolves" would get lost within its content as well. In order to emphasize the serious and melancholic tone of the story, I decided to have students undergo a research project on Native American Boarding schools to provide them with historical context before diving into the story. I considered waiting to see if any students would make the connection themselves and discuss boarding schools in class rather than require a research project. But because my lesson plans 
center around the theme of identity, I wanted students to enter the story ready to draw connections historically and thematically. I believe the research project will also help students have more informed discussions about erasure and assimilation as well as critically examine the story's narration. Examining Claudette's tone was essential for showing the true loss and sadness prevalent in the story. Additionally, Claudette's group speak and use of the terms "pack" and "we" were crucial for displaying the shared experiences of multi individuals as well as the full extent of identity erasure. I was also concerned students would not recognize the story's themes of isolation, so I dedicated several questions to discussing the girls' werewolf parents and their positioning in society.

While my first two stories critically examined the navigation of multi beings in society, I chose the next two stories because of their focus on mixed families in order to examine existing tensions in multi communities. I was worried that by only focusing on the multi themes within "The Americans" and "Who's Irish?" I was neglecting other key themes in the story. I decided to stick to my primary theme but would still recommend educators to revisit the other themes in these stories as well. In both stories, having students recognize the tensions and conflicts surrounding multi identities, without having them believe multi identities can only produce conflict and tension was very important to me. I wanted to show that mixed families are complex without painting them as solely combative. In order to do this, I focused on asking students to explore the similarities and differences between the characters, especially between Carver and Claire. I asked them to analyze their motivations to find belonging, so that they may better understand the cause for their tensions and perhaps see a resolution in the ending. Similarly, in “Who's Irish?” I wanted students to see the problematic language surrounding mixed children and picking "sides" that can exist in families. But I also implored them to see the healthy 
intermingling and exchanging of identity and culture that can also occur in mixed families as seen in my questions about the grandmother's adoption of Bess's dialogue. I also hoped that in discussing the grandmother's positive interactions with Bess, students would see, not a perfect resolution to the story, but a positive future that can still contain tensions and complexities. Asking students to explore the complexities of identity, society, and characters was essential for this lesson plan. Mixed and multi identities are inherently complex, and ensuring that students saw the same complexities throughout each story was the most challenging part of creating this lesson plan. While I have learned that you cannot predict how students will answer or react to a story, posing the right questions is the best way to communicate your lesson goals while still leaving room for student interpretation. I still struggled with narrowing down the number of passages I chose to discuss, in the St. Lucy's lesson plan I may still have too many. Through this I also learned that not everything can be covered in one lesson plan. This in mind, I would perhaps choose to select one story and more deeply analyze it next time.

\section{Works Cited}

Yu, Charles. Third Class Superhero. “Third Class Superhero.” Pages 1-24. Harcourt Books. 2006.

Russell, Karen. St. Lucy's Home for Girls Raised by Wolves. “St. Lucy’s Home for Girls Raised by Wolves.” Pages 225-246. Vintage Books. Random House Inc., New York. 2006.

Nguyen, Viet Thanh. The Refugees. “The Americans.” Pages 125-149. Grove Press, New York. 2017.

Jen, Gish. Who’s Irish? “Who’s Irish?” Pages 1-16. Vintage Books, New York. 1999 Little, Becky. How Boarding Schools Tried to 'Kill the Indian' Through Assimilation. History 
Stories. History.com. August 16, 2017. https://www.history.com/news/how-boardingschools-tried-to-kill-the-indian-through-assimilation

Bear, Charla. American Indian Boarding Schools Haunt Many. Race, National Public Radio. May 12, 2008. https://www.npr.org/templates/story/story.php?storyId=16516865

Howe, John. Unspoken: America's Native American Boarding Schools. Utah History. Public Broadcast System. February 16, 2016. https://www.pbs.org/video/unspoken-americasnative-american-boarding-schools-oobt1r/ 